Canadian

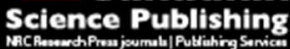

Canadian Journal of Zoology

Revue canadienne de zoologie

\title{
Fatty acid composition and concentration of alternative food of Semipalmated Sandpipers (Calidris pusilla) in the upper Bay of Fundy, Canada
}

\begin{tabular}{|r|l|}
\hline Journal: & Canadian Journal of Zoology \\
\hline Manuscript ID & cjz-2016-0246.R1 \\
\hline Manuscript Type: & Article \\
\hline Complete List of Authors: & $\begin{array}{l}\text { Quinn, Jenna; Mount Allison University, Biology; rare Charitable Research } \\
\text { Reserve } \\
\text { Hamilton, D.J.; Mount Allison University, } \\
\text { Hebert, Craig; National Wildlife Research Centre, Environment and Climate } \\
\text { Change Canada, Science and Technology Branch }\end{array}$ \\
\hline Keyword: & $\begin{array}{l}\text { Semipalmated Sandpiper, Calidris pusilla, fatty acid, biofilm, Corophium } \\
\text { volutator, Bay of Fundy, diet flexibility }\end{array}$ \\
\hline \multicolumn{2}{|c}{} \\
\hline
\end{tabular}

SCHOLARONE

Manuscripts 
1 Fatty acid composition and concentration of alternative food of Semipalmated Sandpipers

2 (Calidris pusilla) in the upper Bay of Fundy, Canada

3 J.T. Quinn, ${ }^{1 \mathrm{a} *}$ D.J. Hamilton, ${ }^{1}$ and C.E. Hebert ${ }^{2}$

$4 \quad{ }^{1}$ Department of Biology, Mount Allison University, Sackville, New Brunswick, Canada

$5 \quad{ }^{2}$ Environment and Climate Change Canada, Science and Technology Branch, National Wildlife

6 Research Centre, Ottawa, Ontario Canada

7 a Current Address: rare Charitable Research Reserve, Cambridge, Ontario, Canada

$8 \quad *$ Corresponding author: jenna.quinn@raresites.org 
Fatty acid composition and concentration of alternative food of Semipalmated Sandpipers Calidris pusilla in the upper Bay of Fundy, Canada

\section{J.T. Quinn, D.J. Hamilton, and C.E. Hebert}

\section{ABSTRACT}

Semipalmated Sandpipers (Calidris pusilla L., 1766) that migrate through the upper Bay of Fundy, Canada, depend on a rich food supply to fuel their continued migration. Although past studies have reported a diet dominated by the amphipod Corophium volutator (Pallas, 1766), an animal rich in n-3 polyunsaturated fatty acids (PUFAs), recent evidence suggests that sandpiper diets are broad. This is beneficial in that it allows Semipalmated Sandpipers to respond to a changing food base, but quality of food is also important. PUFAs are important in providing the energy required by migrating birds and may play a role in migratory preparation. We assessed fatty acid concentrations and proportions in three common food items. We found that polychaetes should adequately meet the needs of migrating sandpipers in terms of fatty acid composition. Concentrations of fatty acids in biofilm were low, but proportionally, n-3 PUFAs were well represented, particularly in biofilm collected in Shepody Bay, where it forms a substantial part of the sandpiper diet. Therefore, provided that birds can consume a sufficient volume of biofilm, it is also probably a suitable source of essential fatty acids. Our results suggest that Semipalmated Sandpipers in the Bay of Fundy can meet their fatty acid needs with a variety of dietary options.

Keywords: Semipalmated Sandpiper, Calidris pusilla, diet flexibility, Bay of Fundy, Corophium volutator, biofilm, fatty acid, PUFA 


\section{INTRODUCTION}

Long distance migration is energetically costly, and migratory birds require substantial energy reserves before undertaking these large-scale annual movements. Energy in the form of carbohydrates, protein, and fat are accumulated in different ratios depending on diet composition (Bairlein 1990), and are not all equally used by avian migrants (Jenni and Jenni-Eiermann 1998).

Fat is an energy-dense fuel source that provides the majority of energy for migrating birds (Gannes 1991; Lindström 1991; Stevens 1996; McWilliams et al. 2004), and includes important fatty acids used to fuel high endurance migration (McWilliams et al. 2004).

Even with the diversity of migratory bird diets, most of the fat stored consists of three fatty acids, palmitic acid (C16:0), oleic acid (C18:1n-9c), and linoleic acid (C18:2n-6c) (McWilliams et al. 2004). These are saturated (SFAs, no double bonds between carbon atoms), monounsaturated (MUFAs, single double bond), and polyunsaturated fatty acids (PUFAs, multiple double bonds) respectively. PUFAs, particularly the short-chained varieties, have been shown to be more easily mobilized than others across a range of taxa, including mammals (Raclot 2003) and both a songbird and shorebird (Price et al. 2008). Both n-3 and n-6 PUFAs are essential fatty acids; there is phylogenetic consistency in the fact that they cannot be efficiently synthesized by vertebrate consumers (Hulbert and Abbott 2011) and must be obtained through dietary sources (Arts et al. 2001). Although limited, existing evidence for birds is consistent with these findings (Iverson et al. 2007; Twining et al. 2016a). Iverson et al. (2007) investigated fatty acids in captive seabirds fed a controlled diet and found little difference in the fatty acid profiles of food and bird tissues, demonstrating little modification of dietary FA profiles by seabirds. Birds with primarily marine diets may have greater access to n-3 PUFAs than birds with terrestrial or fresh-water diets (Hulbert and Abbott 2011; Klaassen et al. 2012; Twining et al. 
54 2016a). According to the adaptive modulation hypothesis (Karasov 1992), pathways for the

55 synthesis of a potentially limiting nutrient, e.g. n-3 PUFA, may be down-regulated in organisms

56 inhabiting environments where nutrient availability is high, e.g. marine ecosystems. This may

57 contribute to dependence on dietary sources of n-3 PUFAs in seabirds. However, reliance on

58 dietary sources of fatty acids in terrestrial birds has also been observed. Twining et al. (2016a)

59 found that Tree Swallow (Tachycineta bicolor (Vieillot, 1808)) chicks (like other vertebrates, see

60 Twining et al. 2016b) have a limited ability to elongate and desaturate possible precursor fatty

61 acids to make long carbon-chain PUFA. Dietary sources of these PUFAs were necessary to meet

62 the physiological requirements of chicks. Dietary fatty acids also play an important role in

63 regulating the fatty acid composition of fat tissue used by birds during migration. There is

64 evidence (reviewed in Pierce and McWilliams 2014) that some songbirds select foods that allow

65 them to achieve particular fatty acid profiles, and that during migration n-6 PUFAs increase in

66 fat stores.

Semipalmated Sandpipers (Calidris pusilla L., 1766) travel to the upper Bay of Fundy,

68 Canada each year and use the site as an important stopover location before their trans-oceanic

69 migration to South America (Hicklin 1987). Corophium volutator (Pallas, 1766), a small

70 burrowing amphipod inhabiting intertidal mudflats in the region, has been considered the

71 dominant prey item for these shorebirds (Hicklin and Smith 1984). C. volutator has a high fatty

72 acid content and is a rich source of n-3 PUFAs, specifically EPA (eicosapentaenoic acid,

$73 \mathrm{C} 20: 5 \mathrm{n} 3$ ) and DHA (docosahexaenoic acid, C22:6n3), which make up $\sim 45 \%$ of their total fatty

74 acid composition (Ackman et al. 1979; Maillet and Weber 2006). Semipalmated Sandpipers

75 make use of n-3 PUFAs as an easily mobilized fuel for migration, and it has been suggested that

76 these fatty acids provide a metabolic signal to prepare flight muscles for endurance (Maillet and 
77 Weber 2006, 2007; Nagahuedi et al. 2009; Weber 2009; but see Guglielmo 2010 and Price $78 \quad 2010)$.

Although C. volutator is undoubtedly a high quality food source, recent evidence

80

81

82 suggests that it may not be as important a part of the Semipalmated Sandpiper diet as previously thought. Populations of this amphipod are highly variable among sites (Barbeau et al. 2009; Gerwing et al. 2015) and have declined substantially in some areas (reviewed in Gerwing et al. 2016). However, birds continue to feed on mudflats, using alternate prey and alternate foraging behaviours, even when C. volutator is rare (MacDonald et al. 2012). Gerwing et al. (2016) concluded that Semipalmated Sandpipers have broad diets and forage opportunistically while in the Bay of Fundy. This is not surprising and has also been documented in other areas of their range (e.g., Skagen and Oman 1996). In the Bay of Fundy, both polychaete worms and biofilm (consisting primarily of diatoms and the extracellular polymeric substances they produce (Trites et al. 2005)) now appear to contribute substantially to the diet (Quinn and Hamilton 2012), and other prey such as ostracods can be important if present in sufficient quantities (MacDonald et al. 2012). The inclusion of biofilm is consistent with recent studies of related shorebird species (Kuwae et al. 2008, 2012; Jardine et al. 2015), in which it has been found to be an important dietary component.

A broad diet is beneficial to Semipalmated Sandpipers when faced with a variable prey base. However, prey quality is as important as quantity. Although adapting to an available prey base may have short term and seasonal benefits, allowing individuals to exploit whatever food source is present, there may be unknown long-term impacts. If alternate prey are of inferior quality and birds are faced with a "Hobson's choice" of consuming poor quality prey or going hungry (sensu Hebert et al. 2008), the result can be declines in body condition and/or 
100 reproductive endpoints, as has been observed with some gull and passerine species (Hebert et al.

101 2002, 2008; Blight 2011; Twining et al. 2016a). Insufficient prey quantity or reduced prey

102 quality, combined with other stressors, may have important implications for migratory avian

103 species (Klaassen et al. 2012). Understanding the relative value of available prey is therefore

104 essential to understand the long-term conservation implications of a variable diet in a species

105 traditionally thought to focus on a high quality food source.

106 We know the inherent value of $C$. volutator in terms of both energy and fatty acid

107 composition (Ackman et al. 1979; Maillet and Weber 2006), and studies in other areas have

108 shown that biofilm and polychaetes all contain some level of n-3 PUFAs (Bühring and

109 Christiansen 2001; Huggins et al. 2004). However, we lack such information about alternative

110 food found in the Bay of Fundy. To address this knowledge gap, we assessed the fatty acid

111 composition of common alternative foods, and compared these values with C. volutator.

112 Although other aspects of food quality such as protein and carbohydrate content are also

113 important, we focused on fatty acids because of the documented link between Semipalmated

114 Sandpipers and C. volutator (Hicklin and Smith 1979, 1984; Hamilton et al. 2003; Sprague et al.

115 2008), and the importance of n-3 PUFAS found in this prey item (Maillet and Weber 2006, 116 2007).

118 METHODS

119 Study Sites

120 We collected prey samples in summer 2010 from three intertidal mudflats in the Upper Bay of

121 Fundy, chosen based on foraging habits of Semipalmated Sandpipers. We worked in Shepody

122 Bay (the western segment of Chignecto Bay), and in the southern bight of Minas Basin. In 
123 Shepody Bay, mudflats sampled were Mary’s Point $\left(45.72^{\circ} \mathrm{N} ; 64.67^{\circ} \mathrm{W}\right)$ and Grande Anse $124\left(45.82^{\circ} \mathrm{N} ; 64.50^{\circ} \mathrm{W}\right)$. In the Minas Basin we sampled at Avonport $\left(45.11^{\circ} \mathrm{N} ; 64.24^{\circ} \mathrm{W}\right)$ (Figure 125 1). In these areas, tides rise and fall by up to $15 \mathrm{~m}$ (Desplanque and Mossman 2004), exposing 126 large mudflats extending $\sim 800$ to $2000 \mathrm{~m}$ from shore at low tide. These are the mudflats used by 127 Gerwing et al. (2016) in their molecular diet analysis. See Gerwing et al. (2015) for details of site 128 characteristics.

\section{Food Collection}

130 Sediment was collected from the top $5 \mathrm{~cm}$ of mud from a minimum of three locations within $131300 \mathrm{~m}$ of shore on each mudflat. Areas with suitable substrate and evidence of invertebrate 132 activity were targeted to ensure that sufficient organisms were collected for analysis. After 133 collection, sediment samples were sieved through a $250 \mu \mathrm{m}$ mesh (Crewe et al. 2001). Retained 134 invertebrates were live sorted into broad taxonomic groups with the aid of a dissecting 135 microscope. Information on relative abundance of the different taxa at each site is provided in 136 Gerwing et al. (2015). We collected biofilm by scraping it from the surface in areas in which it 137 was visible (appearing as a thin green or green-brown mat on the surface of the mud) using a thin 138 spatula and stored it in scintillation vials (Quinn and Hamilton 2012). Some sediment was 139 unavoidably collected with the biofilm, but this was minimized as much as possible, and birds 140 are also known to consume considerable sediment while feeding (Reeder 1951) so what was 141 sampled likely resembles what birds would consume.

\section{Fatty Acid Analysis}

143 Invertebrates and biofilm from each sample were frozen (grouped as C. volutator, polychaetes, 144 and biofilm) in liquid nitrogen vapor at the time of collection. Polychaetes within each sample 145 were pooled because individuals of the different taxa present (see Gerwing et al. 2015) were not 
numerous enough to provide sufficient biomass for separate analyses. Each sample assayed was thus a combination of many individuals, and as such, the result would reflect consumption of multiple individuals by each bird. Samples were transported in a cryoshipper (Taylor-Wharton CX500) to the National Wildlife Research Center in Ottawa, ON, Canada, where they were stored at $-80^{\circ} \mathrm{C}$ until processing and analysis. Fatty acid methyl esters (FAME) were obtained in a three-step process: extraction, derivatization, and quantification on a gas chromatograph (GC).

Details regarding these steps can be found in Hebert et al. (2006) and McMeans et al. (2012). Briefly, samples were homogenized and lipids extracted in chloroform-methanol, centrifuged, and dried. Derivatization was done using BF3-methanol. Resulting FAMEs were measured by GC (Hewlett Packard model 6890N with sampler-tray 7683B) equipped with flame-ionization detector and fused silica column (Supelco SP2560, 100m X 0.25mm, $0.2 \mu \mathrm{m}$ film thickness). Unknown FAMEs were identified by comparing retention times to standards. Final FAME concentrations are based on an internal standard ( $5 \alpha$-cholestane) and calculated using ChemStation software (Agilent Technologies, Santa Clara, California, USA). Results are reported as $\mu \mathrm{g}$ FAME/mg dry weight tissue and as proportions of total FAME concentrations.

\section{Statistical Analysis}

Data were analysed using R 3.1.1 (R Core Team 2014). We assessed parametric statistical assumptions using Shapiro-Wilk normality tests and visual analysis of Q-Q plots, and Levene's test of homogeneity of variance. Multivariate homogeneity of variance was assessed using the Box's $M$ test. Although an arcsine transformation is frequently required for proportion data, most data met assumptions without it, and in the few cases where violations occurred, we corrected them with $\log$ transformations. Multivariate analyses of variance (MANOVAs) were used to investigate differences in fatty acid concentrations and proportions among potential food types 
169

170

171

172

173

174

175

176

177

178

179

180

181

182

183

184

185

186

187

188

189

190

191

and locations. SFAs, MUFAs, and PUFAs were dependent variables, and fixed independent factors were each possible food type and the two arms of the Bay of Fundy: Shepody Bay and Minas Basin. For this analysis, samples from Grande Anse and Mary's Point were combined to represent Shepody Bay because Semipalmated Sandpipers move regularly between the two areas (Sprague et al. 2008; Neima 2017) and therefore their combination best represents what is available to birds in this region of the Bay of Fundy. We further examined PUFAs by running additional MANOVAs using EPA and DHA concentrations and proportions as dependent variables. Multivariate results were evaluated using Pillai's Trace, the most robust of multivariate test statistics available (Tabachnick and Fidell 2007). Significant interactions between food type and arm of the bay were investigated by examining data from each arm of the bay separately. We followed each significant MANOVA with individual univariate ANOVAs.

Dunnett's post hoc tests (Hothorn 2008) were used to compare concentrations and proportions of fatty acids in alternative food items to levels observed in C. volutator.

\section{RESULTS}

Overall fatty acid concentrations varied with food type (MANOVA $F_{[6,44]}=38.9 ; p<0.001$ ), but not location (MANOVA $F_{[3,21]}=1.0 ; p=0.41$ ), and differences among foods were not substantially different between arms of the bay (MANOVA interaction $F_{[6,44]}=1.7, p=0.15$ ). All fatty acid groups (SFA, MUFA, PUFA) differed among foods (Table 1). C. volutator had significantly higher concentrations of MUFAs than all other potential food items $(p \leq 0.003)$, and higher concentrations of SFAs and PUFAs than biofilm $(p<0.001$; Fig. $2 a)$. However, concentrations of PUFAs and SFAs were similar between $C$. volutator and polychaetes $(p>0.3$,

Fig. 2a). The overall fatty acid composition (proportion of each fatty acid group within each food 
192 type) varied with a combination of bay and food type (MANOVA interaction $F_{[6,44]}=3.7$,

$193 p=0.004)$. In Shepody Bay, the proportions of SFAs, MUFAs, and PUFAs did not differ

194 significantly among food types (MANOVA $F_{[6,24]}=1.0, p=0.47$, Fig. $2 b$ ). In Minas Basin, there 195 were differences among foods (MANOVA $F_{[6,18]}=20.5, p<0.001$ ), and these were present in all 196 categories of fatty acids (Table 1 and Fig. $2 b$ ). There were proportionally less SFAs in $C$.

197 volutator than in polychaetes or biofilm $(p \leq 0.002$, Fig. $2 b)$. However, $C$. volutator contained 198 proportionally more MUFAs than did polychaetes $(p=0.003)$ and more PUFAs than did biofilm $199(p<0.001$, Fig. 2b).

There was an overall multivariate difference among food types in concentrations of the n3 PUFAs EPA and DHA (MANOVA $F_{[4,46]}=30.7 ; p \leq 0.001$ ) but no effect of arm of the bay

202 (MANOVA $F_{[2,22]}=0.1 ; p=0.93$ ). Differences among food types were present for both fatty 203 acids (Table 2). C. volutator had significantly higher concentrations of DHA than other food 204 types $(p \leq 0.002)$, and higher concentrations of EPA than biofilm $(p \leq 0.001)$, but not 205 polychaetes ( $p=0.49$, Fig. $3 a$ ). Proportions of DHA and EPA (relative to total fatty acid concentration per food item) varied with a combination of bay and food type (MANOVA

207 interaction $\left.F_{[4,46]}=8.0, p<0.001\right)$. In Shepody Bay, food types differed in fatty acid composition 208 (MANOVA $F_{[4,26]}=3.3, p=0.03$ ). This was driven by EPA (Table 2), with the EPA proportion 209 higher in both polychaetes and biofilm than in $C$. volutator $(p \leq 0.002$, Fig. $3 b)$. Proportion of 210 DHA was similar among food items (Table 2). In Minas Basin, food types also differed in fatty 211 acid composition (MANOVA $F_{[4,20]}=30.2, p<0.001$ ), but in this case both DHA and EPA 212 contributed to the differences (Table 2). C. volutator and polychaetes had higher proportions of 213 EPA than did biofilm $(p<0.001)$, but $C$. volutator and polychaetes were similar $(p=0.92$, Figure $2143 b)$. DHA was present in higher proportions in $C$. volutator than either biofilm $(p<0.001)$ or 
215 polychaetes $(p=0.001$, Fig. $3 b)$.

216

217 DISCUSSION

218 Corophium volutator is a well-recognized prey item for Semipalmated Sandpipers in the upper

219 Bay of Fundy (Hicklin and Smith 1984), and is a rich source of n-3 PUFAs, which may be 220 important to Semipalmated Sandpipers in preparation for migration (Maillet and Weber 2006,

221 2007). C. volutator fatty acid levels in our study correspond well with those found in previous

222 work (Ackman et al. 1979; Maillet and Weber 2006), suggesting that these animals are a

223 consistent source of essential fatty acids in the Bay of Fundy. Given recent evidence that

224 Semipalmated Sandpipers in the region consume a broad diet (MacDonald et al. 2012; Quinn and

225 Hamilton 2012; Gerwing et al. 2016), fatty acid concentrations and profiles of alternate food

226 items, relative to $C$. volutator, should be considered.

\section{Quality of alternative foods}

228 Polychaetes. Although they have historically been a limited part of the diet of Semipalmated 229 Sandpipers in the Bay of Fundy region (Hicklin and Smith 1979, 1984), recent work suggests 230 that polychaetes now form a large component of the sandpiper diet (Ginn 2009; Quinn and 231 Hamilton 2012; Neima 2017). This is not surprising because relative availability of C. volutator 232 and polychaetes has changed over the past several decades. Whereas $C$. volutator used to be the 233 most abundant invertebrate at many feeding sites, it is now less abundant in some areas, and 234 polychaetes have increased (reviewed in Gerwing et al. 2016). Further, given the considerable 235 evidence that these prey are also used at other stopover sites (Michaud and Ferron 1986;

236 Tsipoura and Burger 1999), knowing the quality of polychaetes is particularly important.

237 Our results suggest that a diet rich in polychaetes will provide Semipalmated Sandpipers 
238 foraging in the Bay of Fundy with essential fatty acids needed for migration, making this prey

239 item a suitable alternative to $C$. volutator. Fatty acid concentrations and proportions in

240 polychaetes varied only slightly from C. volutator. MUFA concentrations were lower, but the

241 essential n-3 PUFA values were comparable in concentration and in proportion. Specific makeup

242 varied, with polychaetes lower in DHA concentration and proportion than C. volutator, but

243 similar or higher in EPA (Fig. 3). EPA and DHA have been suggested to be especially important

244 in preparation for migration, stimulating an increased oxidative capacity of muscles and acting as

245 a natural doping agent for these birds as they rapidly prepare for a long endurance flight (Maillet

246 and Weber 2006; Nagahuedi et al. 2009; Weber 2009; but see Guglielmo 2010 and Price 2010);

247 however, all high PUFA diets are known to increase membrane fluidity and permeability (Ernst

248 1989).

249 Biofilm. Semipalmated Sandpipers foraging in the Bay of Fundy are incorporating biofilm into

250 their diet (MacDonald et al. 2012; Quinn and Hamilton 2012; Gerwing et al. 2016). Use of

251 biofilm by these birds is consistent with work on other shorebirds (Mathot et al. 2010; Kuwae et

252 al. 2012). Kuwae et al. (2008) suggested that biofilm made up 45-49\% of the diet of Western

253 Sandpipers (Calidris mauri (Cabanis, 1857)), and contributed 50\% of sandpipers' daily energy

254 requirement. Jardine et al. (2015), using stable isotope analyses of droppings, estimated the

255 biofilm contribution to the diet at 22 to $53 \%$.

The biofilm collected at our study sites appears to offer less than $2 \%$ of the

257 concentrations of SFA, MUFA, and PUFA provided by C. volutator. This is a surprising result,

258 as diatoms are known to be an important source of fatty acids (Huggins et al. 2004), particularly

259 some longer-chain PUFAs (Ackman et al. 1964; Dunstan et al. 1993), and diatoms make up the

260 majority of microphytobenthos on mudflats in the Bay of Fundy (Trites et al. 2005). 
261 Concentration and quality of fatty acids in diatoms varies with season, ultraviolet radiation, light, 262 and species (Dunstan et al. 1993; Huggins et al. 2004; Guihéneuf et al. 2010; Chen 2012), so it is

263 possible that the conditions present on our mudflats are not conducive to high fatty acid

264 concentrations. However, it is far more likely that our sampling method substantially

265 underestimated concentrations of fatty acids in biofilm samples. We scraped biofilm off the mud 266 surface, and although every effort was made to avoid picking up sediment, small amounts of it 267 were incorporated into each sample. Sediment may thus have diluted the fatty acid concentration 268 measured in biofilm. However, shorebirds also take in sediment when foraging; it forms up to $26975 \%$ of stomach contents in some cases (Reeder 1951; Tsipoura and Burger 1999; Kuwae et al. 270 2008; Mathot et al. 2010). Thus, the fatty acid values of biofilm determined here may reflect 271 what is ingested by shorebirds. In this case, birds may need to consume large quantities of 272 biofilm to obtain quantities of fatty acids comparable to what they get from consuming $C$.

273 volutator. Kuwae et al. (2008) found that individual Western Sandpipers could consume $\sim 190 \mathrm{~g}$ of 275 wet biofilm per day, seven times their body mass. Therefore, high volume consumption is clearly 276 possible. Given this, food quality in terms of relative proportions of fatty acids, and in particular 277 the proportion of n-3 PUFAs, is an important consideration. Overall, biofilm consisted of $\sim 40 \%$ 278 SFAs (myristic acid C14:0, pentadecanoic acid C15:0, palmitic acid, stearic acid C18:0), 20\% 279 MUFAs (palmitoleic acid C16:1n7, oleic acid) and 40\% PUFAs (linoleic acid, alpha-linolenic 280 acid C18:3n3, arachidonic acid C20:4n6, docosapentaenoic acid C22:5n3, EPA, and DHA) (see 281 Appendix Table A1). Although spatially variable, n-3 PUFAs were well represented among fatty 282 acids in biofilm. Within Shepody Bay, this distribution of fatty acids was consistent with $C$. 283 volutator (see Fig. 2b). In Minas Basin, biofilm contained proportionally more SFAs and less 
PUFAs than did C. volutator, perhaps driven by a combination of lower DHA and EPA proportions. Our results suggest that if birds consume enough biofilm, it may be appropriate to meet their dietary needs with respect to fatty acids.

It is notable that during the period when these data were collected, biofilm comprised a substantially higher proportion of the diet of sandpipers foraging in Shepody Bay than in Minas Basin (Quinn and Hamilton 2012). Differences between the arms of the bay in biofilm quality may reflect different species composition or growing conditions (Dunstan et al. 1993; Huggins et al. 2004; Guihéneuf et al. 2010). Although assessment of that is outside the scope of this study, future work should include a more detailed study of local biofilm composition and fatty acid profiles relative to dietary proportions in shorebirds using these areas.

\section{Implications of a Changing Food Base}

While we used to view $C$. volutator as a critical resource that was an important basis for habitat selection and foraging activity by Semipalmated Sandpipers (Hicklin and Smith 1979, 1984; Hamilton et al. 2003; Sprague et al. 2008), we now recognize that it was probably just a widely available high quality food source for birds. Sandpipers appear to be opportunistic foragers with diverse diets (MacDonald et al. 2012; Quinn and Hamilton 2012; Gerwing et al. 2016). The change in food habits, particularly the increase in importance of polychaetes, may simply reflect the changing prey base. Consumption of biofilm is probably not a new phenomenon for this species; historical diet studies (Hicklin and Smith 1979, 1984) did not report it, but those studies focused on invertebrate prey. Western Sandpipers are known to graze on biofilm (Kuwae et al. 2008; Jardine et al. 2015), and Semipalmated Sandpipers engage in similar behaviour, particularly at night (Hebert 2011; Quinn 2011). Recent observations (S.G. Neima personal communication) suggest that Semipalmated Sandpipers possess the same tongue adaptations 
307 308

observed in related species that consume biofilm (described in Elner et al. 2005). Therefore, it seems highly unlikely that these birds have only recently acquired a biofilm foraging habit. However, it is possible that proportions in the diet have shifted as the food base has changed. Regardless, additional work to accurately quantify concentrations of n-3 PUFAs, as well as other energy sources, in biofilm is warranted.

Our results suggest that a diet rich in polychaetes, and incorporating biofilm, could provide the necessary fatty acid profile to prepare birds for migration and thus is not a "Hobson's Choice" for sandpipers- at least not in the context of limiting fatty acid availability. Our findings should not be surprising if Semipalmated Sandpipers select for diets high in specific fatty acids, as seen in other birds (Bairlein and Gwinner 1994; Pierce et al. 2005). Such selection could be assessed by examining fatty acid profiles in a broader range of possible food items. An analysis of energetic content of food would also be informative, as would further investigation into other energy sources such as protein and carbohydrates, as recent evidence suggests some level of protein in diets is important to transport fatty acids to working muscles (Guglielmo 2010). Our findings are encouraging in that it appears that Semipalmated Sandpipers foraging in the Bay of Fundy have the capacity to obtain essential fatty acids from a range of food types, offering them foraging flexibility as they prepare for migration.

\section{ACKNOWLEDGEMENTS}

We are grateful to field and laboratory staff from Mount Alison University and to M. Barbeau and her lab at the University of New Brunswick- Fredericton who assisted with this study, and the Canadian Wildlife Service and Nature Conservancy of Canada for access to field sites and equipment. We thank A. Redden for access to the ACER lab, and the Mary's Point and 
Johnson's Mills Shorebird Interpretive Centres for their support. Thanks to M. Forbes for transporting samples and to A. Caron (NWRC) for conducting the fatty acid analyses. Comments from two anonymous reviewers, together with discussions with R. Elner, substantially improved the manuscript. Funding and equipment were provided by a Natural Sciences and Engineering Research Council (NSERC) Strategic Projects Grant, NSERC Discovery Grant, NSERC

Research Tools and Instruments Grant, Mount Allison University, and Environment and Climate Change Canada's Science and Technology Branch.

\section{REFERENCES}

Ackman, R.G., Nash, D.M., and McLaughlin, J. 1979. Lipids and fatty-acids of Corophium volutator from Minas Basin. Proc. Nova Scotia Inst. Sci. 29(4):501-516.

Ackman, R.G., Jangaard, P.M., Hoyle, R.J., and Brockerhoff, H. 1964. Origin of marine fatty acids. I. Analyses of the fatty acids produced by the diatom Skeletonema costatum. J. Fish. Res. Board Can. 21(4):747-756. doi: 10.1139/f64-067.

Arts, M.T., Ackman, R.G., and Holub, B.J. 2001. "Essential fatty acids" in aquatic ecosystems: a crucial link between diet and human health and evolution. Can. J. Fish. Aquat. Sci. 58(1):122-137. doi: 10.1139/cjfas-58-1-122.

Bairlein, F. 1990. Nutrition and food selection in migratory birds. In Bird migration: physiology and ecophysiology. Edited by E. Gwinner. Spring, New York, pp. 198-213.

Bairlein, F., and Gwinner, E. 1994. Nutritional mechanisms and temporal control of migratory energy accumulation in birds. Annu. Rev. Nutr. 14:187-215. doi: 10.1146/annurev.nu.14.070194.001155.

Barbeau, M.A., Grecian, L.A., Arnold, E.E, Sheahan, D.C., and Hamilton, D.J. 2009. Spatial and temporal variation in the population dynamics of the intertidal amphipod Corophium 
volutator in the Upper Bay of Fundy, Canada. J. Crustac. Biol. 29:491-506. doi: 10.1651/08-3067.1.

Blight, L.K. 2011. Egg production in a coastal seabird, the Glaucous-Winged Gull (Larus glaucescens), declines during the last century. PLoS One, 6(7):e22027. doi: doi:10.1371/journal.pone.0022027.

Bühring, S.I., and Christiansen, B. 2001. Lipids in selected abyssal benthopelagic animals: links to the epipelagic zone? Prog. Oceanogr. 50(1-4):369-382.

Chen, Y.C. 2012. The biomass and total lipid content and composition of twelve species of marine diatoms cultured under various environments. Food Chem. 131(1):211-219. doi:10.1016/j.foodchem.2011.08.062.

Crewe, T.L., Hamilton, D.J., and Diamond, A.W. 2001. Effects of mesh size on sieved samples of Corophium volutator. Estuar. Coast. Shelf Sci. 53(2):151-154. doi:10.1006/ecss.2001.0795.

Desplanque, C., and Mossman, D.J. 2004. Tides and their seminal impact on the geology, geography, history, and socio-economics of the Bay of Fundy, eastern Canada. Atl. Geol. 40:1-130.

Dunstan, G.A., Volkman, J.K., Barrett, S.M, Leroi, J.M., and Jeffrey, S.W. 1993. Essential polyunsaturated fatty acids from 14 species of diatom (Bacillariophyceae). Phytochemistry, 35(1):155-161. doi:10.1016/S0031-9422(00)90525-9.

Elner, R.W., Beninger, P.G., Jackson, D.L, and Potter, T.M. 2005. Evidence of a new feeding mode in western sandpiper (Calidris mauri) and dunlin (Calidris alpina) based on bill and tongue morphology and ultrastructure. Mar. Biol. 146(6):1223-1234. doi:10.1007/s00227004-1521-5. 
376

377

378

379

380

381

382

383

384

385

386

387

388

389

390

391

392

393

394

395

396

Ernst, E. 1989. Effects of n-3 fatty acids on blood rheology. J. Intern. Med. Suppl.

225(S731):129-132. doi: 10.1111/j.1365-2796.1989.tb01446.x.

Gannes, L.Z. 2001. Comparative fuel use of migrating passerines: effects of fat stores, migration distance, and diet. Auk, 118(3):665-677. doi: http://dx.doi.org/10.1642/00048038(2001)118[0665:CFUOMP]2.0.CO;2.

Gerwing, T.G., Gerwing, A.M.A., Drolet, D., Barbeau, M.A., and Hamilton, D.J. 2015. Spatiotemporal variation in biotic and abiotic features of eight intertidal mudflats in the upper Bay of Fundy, Canada. Northeast. Nat. 22(m12):1-44. doi: http://dx.doi.org/10.1656/045.022.m1201.

Gerwing, T.G., Kim, J.H., Hamilton, D.J., Barbeau, M.A., and Addison, J.A. 2016. Diet reconstruction using next-generation sequencing increases the known ecosystem usage by a shorebird. Auk, 133(2):168-177. doi: http://dx.doi.org/10.1642/AUK-15-176.1.

Ginn, M.G. 2009. Flexibility in foraging behaviour and use of alternative food sources by semipalmated sandpipers (Calidris pusilla) during migratory stopover in the upper Bay of Fundy. M.Sc. thesis, Mount Allison University, Sackville, NB, Canada.

Guglielmo, C.G. 2010. Move that fatty acid: fuel selection and transport in migratory birds and bats. Integr. Comp. Biol. 50(3):336-345. doi: 10.1093/icb/icq097.

Guihenéuf, F., Fouqueray, M., Mimouni, V., Ulmann, L., Jacquette, B., and Tremblin, G. 2010. Effects of UV stress of the fatty acid and lipid class composition in two marine microalgae Pavlova lutheri (Pavlovphyceae) and Odontella aurita (Bacillariophyceae). J. Appl. Phycol. 22(5):629-638. doi:10.1007/s10811-010-9503-0. 
397 398

Hamilton, D.J., Barbeau, M.A., and Diamond, A.W. 2003. Shorebirds, mud snails, and Corophium volutator in the upper Bay of Fundy, Canada: predicting bird activity on intertidal mud flats. Can. J. Zool., 18:1358-1366. doi: 10.1139/Z03-13.

Hebert, C.E., Shutt, J.L., and Ball, R.O. 2002. Plasma amino acid concentrations as an indicator of protein availability to breeding Herring Gulls (Larus argentatus). Auk, 119(1):185-200. doi: http://dx.doi.org/10.1642/0004-8038(2002)119[0185:PAACAA]2.0.CO;2.

Hebert, C.E., Arts, M.T., and Weseloh, D.V. 2006. Ecological tracers can quantify food web structure and change. Environ. Sci. Technol. 40(18):5618-5623. doi: 10.1021/es0520619.

Hebert, C.E., Weseloh, D.V.C., Idrissi, A., Arts, M.T., O’Gorman, R., Gorman, O.T., Locke, B., Madenjian, C.P., and Roseman, E.F. 2008. Restoring piscivorous fish populations in the Laurentian Great Lakes causes seabird dietary change. Ecology, 89(4):891-897. doi: 10.1890/07-1603.1.

Hebert, M.A. 2011. Diurnal and nocturnal foraging activities of Semipalmated Sandpipers (Calidris pusilla) in the upper Bay of Fundy. B.Sc. Hons thesis, Mount Allison University, Sackville, NB, Canada.

Hicklin, P.W. 1987. The migration of shorebirds in the Bay of Fundy. Wilson Bull. 99(4):540570.

Hicklin, P.W., and Smith, P.C. 1979. The diets of five species of migrant shorebirds in the Bay of Fundy. Proc. Nova Scotia Inst. Sci. 29(4):483-488.

Hicklin, P.W., and Smith, P.C. 1984. Selection of foraging sites and invertebrate prey by migrant Semipalmated Sandpipers, Calidris pusilla (Pallas), in Minas Basin, Bay of Fundy. Can. J. Zool. 62(11):2201-2210. doi: 10.1139/z84-321. 
Hothorn, T., Bretz, F., and Westfall, P. 2008. Simultaneous inference in general parametric models. Biometrical J. 50(3):346-363. doi: 10.1002/bimj.200810425.

Huggins, K., Frenette, J.J., and Arts, M.T. 2004. Nutritional quality of biofilms with respect to light regime in Lake Saint-Pierre (Québec, Canada). Freshw. Biol. 49(7):945-959. doi: 10.1111/j.1365-2427.2004.01236.x.

Hulbert, A.J., and Abbott, S.K. 2011. Nutritional ecology of essential fatty acids: an evolutionary perspective. Aust. J. Zool. 59(6):369-379. doi: http://dx.doi.org/10.1071/ZO11064.

Iverson, S.J., Springer, A.M., and Kitaysky, A.S. 2007. Seabirds as indicators of food web structure and ecosystem variability: qualitative and quantitative diet analyses using fatty acids. Mar. Ecol. Prog. Ser. 352:235-244. doi:10.3354/meps07073.

Jardine, C.B., Bond, A.L., Davidson, P.J.A., Butler, R.W., and Kuwae, T. 2015. Biofilm consumption and variable diet composition of Western Sandpipers (Calidris mauri) during migratory stopover. PLoS One, 10(4):e0124164. doi:10.1371/journal.pone.012416.4

Jenni, L., and Jenni-Eiermann, S. 1998. Fuel supply and metabolic constraints in migrating birds. J. Avian Biol. 29:521-528.

Karasov, W.H. 1992. Tests of the adaptive modulation hypothesis for dietary control of intestinal nutrient transport. Am. J. Physiol. Regul. Integr. Comp. Physiol. 263(3):496-502.

Klaassen, M., Hoye, B.J., Nolet, B.A., and Buttemer, W.A. 2012. Ecophysiology of avian migration in the face of current global hazards. Philos. Trans. R. Soc. Lond. B Biol. Sci. No. 367:1719-1732. doi: 10.1098/rstb.2012.0008.

Kuwae, T., Beninger, P.G., Decottignies, P., Mathot, K.J., Lund, D.R., and Elner R.W. 2008. Biofilm grazing in a higher vertebrate: the Western Sandpiper (Calidris mauri). Ecology, 89(3):599-606. doi: 10.1890/07-1442.1. 
442 Kuwae, T., Miyoshi, E., Hosokawa, S., Ichimi, K., Hosoya, J., Amano, T., Moriya, T., Kondoh, 443 M., Ydenberg, R.C., and Elner, R.W. 2012. Variable and complex food web structures

444 445

446 447 448 449 450 451 452 453 454 455 456 457 458 459 460 revealed by exploring missing trophic links between birds and biofilm. Ecol. Lett. 15(4):347-356. doi: 10.1111/j.1461-0248.2012.01744.x.

Lindström, Å. 1991. Maximum fat deposition rates in migrating birds. Ornis Scand. 22(1):12-19. doi: $10.2307 / 3676616$.

MacDonald, E.C., Ginn, M.G., and Hamilton, D.J. 2012. Variability in foraging behaviour and implications for diet breadth among Semipalmated Sandpipers staging in the upper Bay of Fundy. Condor, 114(1):135-144. doi: http://dx.doi.org/10.1525/cond.2012.100246.

Maillet, D., and Weber, J.M. 2006. Performance-enhancing role of dietary fatty acids in a longdistant migrant shorebird: the Semipalmated Sandpiper. J Exp. Biol. 209:2686-2695. doi: 10.1242/jeb.02299.

Maillet, D., and Weber, J.M. 2007. Relationship between n-3 PUFA content and energy metabolism in the flight muscles of a migrating shorebird: evidence for natural doping. J. Exp. Biol. 210:413-420. doi: 10.1242/jeb.02660.

Mathot, K.J., Lund, D.R., and Elner, R.W. 2010. Sediment in stomach contents of Western Sandpipers and Dunlin provide evidence of biofilm feeding. Waterbirds, 33(3):300-306. doi: http://dx.doi.org/10.1675/063.033.0305.

McMeans, B.C., Arts, M.T., Rush, S.A., and Fisk, A.T. 2012. Seasonal patterns in fatty acids and stable isotopes of Calanus hyperboreus (Copepoda, Calanoida) from Cumberland Sound, Baffin Island. Mar. Biol. 159(5):1095-1105. doi: 10.1007/s00227-012-1889-6. 
McWilliams, S.R., Guglielmo, C., Pierce, B., and Klassen, M. 2004. Flying, fasting, and feeding in birds during migration: a nutritional and physiological ecology perspective. J. Avian Biol. 35(5):377-393. doi: 10.1111/j.0908-8857.2004.03378.x.

Michaud, G., and Ferron, J. 1986. Etude comparative des techniques de quete alimentaire de quatre especes d'oiseaux limicoles. Nat. Can. (Qué) 113:281-292.

Nagahuedi, S., Popesku, J.T., Trudeau, V.L., and Weber, J.M. 2009. Mimicking the natural doping of migrant sandpipers in sedentary quails: effects of dietary n-3 fatty acids on muscle membranes and PPAR expression. J. Exp. Biol. 212:1106-1114. doi: 10.1242/jeb.027888.

Neima, S.G. 2017. Stopover ecology of Semipalmated Sandpipers (Calidris pusilla) during fall migration through the upper Bay of Fundy, Canada. M.Sc. thesis, Mount Allison University, Sackville, NB, Canada.

Pierce, B.J., McWilliams, S.R., O’Connor, T.P., Place, A.R., and Guglielmo, C.G. 2005. Effect of dietary fatty acid composition on depot fat and exercise performance in a migrating songbird, the Red-Eyed Vireo. J. Exp. Biol. 208:1277-1285. doi: 10.1242/jeb.01493.

Pierce, B.J., and McWilliams, S.R. 2014. The fat of the matter: how dietary fatty acids can affect exercise performance. Integr. Comp. Biol. 54(5):903-912. doi:10.1093/icb/icu098.

Price, E.R., Krokfors, A., and Guglielmo, C.G. 2008. Selective mobilization of fatty acids from adipose tissue in migratory birds. J. Exp. Biol. 211:29-24.

Price, E.R. 2010. Dietary lipid composition and avian migratory flight performance: development of a theoretical framework for avian fat storage. Comp. Biochem. Physiol. A Mol. Integr Physiol. 157(4):297-309. doi: http://dx.doi.org/10.1016/j.cbpa.2010.05.019. 
485 Quinn, J.T. 2011. Dietary flexibility and diurnal and nocturnal foraging behaviour of

486 Semipalmated Sandpipers (Calidris pusilla) in the upper Bay of Fundy, Canada: Links to

487

488

489

490

491

492

493

Quinn, J.T., and Hamilton, D.J. 2012. Variation in diet of Semipalmated Sandpipers (Calidris prey availability and quality. M.Sc. thesis, Mount Allison University, Sackville, NB, Canada. pusilla) during stopover in the upper Bay of Fundy, Canada. Can. J. Zool. 90(9):11811190. doi:10.1139/Z2012-086.

R Core Team 2014. R: A language and environment for statistical computing. R Foundation for Statistical Computing, Vienna, Austria. URL https:/www.R-project.org/.

494

495

Raclot, T. 2003. Selective mobilization of fatty acids from adipose tissue triacylglycerols. Prog. Lipid Res. 42:257-288.

496

Reeder, W.G. 1951. Stomach analysis of a group of shorebirds. The Condor, 53(1):43-45. DOI:

497 $10.2307 / 1364586$.

498

Skagen, S.K. and Oman, H.D. 1996. Dietary flexibility of shorebirds in the western hemisphere. Can. Field-Nat. 110(4):419-444.

500

Sprague, A. J., Hamilton, D.J., and Diamond, A.W. 2008. Site safety and food affect movements of Semipalmated Sandpipers (Calidris pusilla) migrating through the upper Bay of Fundy. Avian Conserv. Ecol. 3:4. Available from http://www.ace-eco.org/vol3/iss2/art4/ [accessed 15 December 2008].

504 Stevens, L. 1996. Avian Biochemistry and Molecular Biology. Cambridge University Press, $505 \quad$ Cambridge.

506 Tabachnick, B.G., and Fidell, L.S. 2007. Using multivariate statistics, 5th edition. Pearson 507 Education, Boston, Massachusetts. 
508 Trites, M., Kaczmarska, I., Ehrman, J.M., Hicklin, P.W., and Ollerhead, J. 2005. Diatoms from 509 two macro-tidal mudflats in Chignecto Bay, Upper Bay of Fundy, New Brunswick, 510 Canada. Hydrobiologia, 544:299. doi:10.1007/s10750-005-1696-x.

511 Tsipoura, N., and Burger, J. 1999. Shorebird diet during spring migration stopover on Delaware 512 Bay. Condor, 101(3):635-644. doi: 10.2307/1370193.

513 Twining, C.W, Brenna, J.T., Lawrence, P., Shipley, J.R., Tollefson, T.N., and Winkler, D.W. 514 2016a. Omega-3 long-chain polyunsaturated fatty acids support aerial insectivore performance more than food quantity. Proc. Natl. Acad. Sci. U.S.A. 113(39):10920-10925.

516 doi:10.1073/pnas.1603998113.

517 Twining, C.W., Brenna, J.T., Hairston, N.G., and Flecker, A.S. 2016b. Highly unsaturated fatty 518 acids in nature: what we know and what we need to learn. Oikos, 125:749-760.

519 doi:10.111/oik.02910.

520 Weber, J-M. 2009. The physiology of long-distance migration: extending the limits of endurance 521 metabolism. J. Exp. Biol. 212:593-597. doi: 10.1242/jeb.015024. 
524 Table 1. Results of univariate ANOVAs conducted following significant MANOVA results

525 (reported in the text) for analyses of concentrations and proportions of SFAs, MUFAs, and

526 PUFAs in food items collected in Shepody Bay and Minas Basin. For proportions, a significant

527 multivariate interaction required separate analyses for the two areas. There were no significant

528 multivariate effects in Shepody Bay (see text), so univariate analyses are not reported. For

529 significant main effects, post hoc comparisons among food types are presented in the text.

530

\begin{tabular}{|c|c|c|c|c|c|}
\hline Measure & Fatty acid group & Factor & $\overline{d f}$ & $\bar{F}$ & $\bar{P}$ \\
\hline \multirow[t]{9}{*}{ concentration } & SFA & location & 1,23 & 0.7 & 0.43 \\
\hline & & food type & 2,23 & 269.6 & $<0.001$ \\
\hline & & location*food type & 2,23 & 1.5 & 0.25 \\
\hline & MUFA & location & 1,23 & 0.7 & 0.42 \\
\hline & & food type & 2,23 & 137.6 & $<0.001$ \\
\hline & & $\begin{array}{l}\text { location* food } \\
\text { type }\end{array}$ & 2,23 & 0.6 & 0.55 \\
\hline & PUFA & location & 1,23 & 0.1 & 0.82 \\
\hline & & food type & 2,23 & 301.9 & $<0.001$ \\
\hline & & $\begin{array}{l}\text { location* food } \\
\text { type }\end{array}$ & 2,23 & 0.2 & 0.84 \\
\hline \multirow[t]{3}{*}{ proportion } & SFA - Minas Basin & food type & 2,10 & 49.6 & $<0.001$ \\
\hline & MUFA - Minas Basin & food type & 2,10 & 24.5 & $<0.001$ \\
\hline & PUFA - Minas Basin & food type & 2,10 & 66.7 & $<0.001$ \\
\hline
\end{tabular}


531 Table 2. Results of univariate ANOVAs conducted following significant MANOVA results

532 (reported in the text) for analyses of concentrations and proportions of the n-3 PUFAs EPA and

533 DHA in food items collected in Shepody Bay and Minas Basin. For proportions, a significant

534 multivariate interaction required separate analyses for the two areas. For significant main effects,

535 post hoc comparisons among food types are presented in the text.

\begin{tabular}{|c|c|c|c|c|c|}
\hline measure & Fatty acid group & factor & $\mathrm{df}$ & $F$ & $P$ \\
\hline \multirow[t]{6}{*}{ concentration } & EPA & location & 1,23 & 0.1 & 0.70 \\
\hline & & food type & 2,23 & 478.0 & $<0.0001$ \\
\hline & & $\begin{array}{l}\text { location*food } \\
\text { type }\end{array}$ & 2,23 & 0.1 & 0.95 \\
\hline & DHA & location & 1,23 & $<0.1$ & 0.90 \\
\hline & & food type & 2,23 & 474.5 & $<0.0001$ \\
\hline & & $\begin{array}{l}\text { location* food } \\
\text { type }\end{array}$ & 2,23 & 0.1 & 0.87 \\
\hline \multirow[t]{2}{*}{ proportion } & EPA - Shepody Bay & food type & 2,13 & 11.9 & 0.001 \\
\hline & DHA - Shepody Bay & food type & 2,13 & 1.6 & 0.23 \\
\hline \multirow[t]{2}{*}{ proportion } & EPA - Minas Basin & food type & 2,10 & 60.2 & $<0.0001$ \\
\hline & DHA - Minas Basin & food type & 2,10 & 35.5 & 0.0001 \\
\hline
\end{tabular}




\section{FIGURE CAPTIONS}

539 Figure 1. Locations of sampled mudflats within the upper Bay of Fundy, New Brunswick and

540 Nova Scotia, Canada. See also Figure 1 in Gerwing et al. (2016).

541 Figure 2. a) Concentration ( $\mu \mathrm{g}$ FAME/mg dry weight) and $\boldsymbol{b}$ ) proportions (relative to total FA

542 composition) of saturated (SFA), monounsaturated (MUFA), and polyunsaturated fatty acids

543 (PUFA) for each food type from Shepody Bay and Minas Basin. $n=3-8$ (see Appendix Table

544 A1). Within each boxplot, the horizontal line represents the median, margins of the box the 545 interquartile range (IQR), and whiskers all points that are within $1.5 *$ IQR of the hinge. Points

546 beyond that range are plotted individually. Results of statistical comparisons are presented in 547 Table 1 and in the text.

548 Figure 3. a) Concentration ( $\mu \mathrm{g}$ FAME/mg dry weight) and $\boldsymbol{b}$ ) proportions (relative to total FA 549 composition) of DHA and EPA for each food type from Shepody Bay and Minas Basin. $n=3-8$

550 (see Appendix Table A1). Within each boxplot, the horizontal line represents the median, 551 margins of the box the interquartile range (IQR), and whiskers all points that are within $1.5 *$

552 IQR of the hinge. Points beyond that range are plotted individually. Results of statistical 553 comparisons are presented in Table 2 and in the text. 
555 APPENDICES

556

557 Table A1: Fatty acid composition of three available food options for Semipalmated Sandpipers (Calidris

558 pusilla L., 1766) averaged over each arm of the Bay of Fundy. Results are reported as $\mu \mathrm{g}$ FAME/mg

559 dry weight tissue \pm SD. When a particular fatty acid was not detected in any samples, a value of

5600 is entered. Sample size indicates the number of samples processed separately for each food

561 type. Each sample consisted of a combination of multiple individual organisms (continued on

562 next page).

Saturated fatty acids

C13:0

C14:0

C15:0

C16:0

C17:0

C18:0

C20:0

C21:0

C22:0

C23:0

C24:0

$\sum$ SFAs

Monounsaturated fatty acids

C15:1n5c

C16:1n7

$\mathrm{C} 18: \ln 9 \mathrm{t}$
Minas Basin

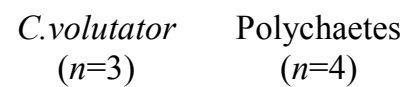

$(n=3)$

0

$0.53 \pm 0.24$

0

$0.16 \pm 0.06$

$5.99 \pm 1.60$

$0.17 \pm 0.04$

$0.58 \pm 0.15$

$2.20 \pm 0.70$

$0.99 \pm 0.15$

0

0

0

0

0

$7.83 \pm 2.03$

$7.60 \pm 2.20$

0

$2.46 \pm 1.16$

0
$0.29 \pm 0.19 \quad 0$

$0.99 \pm 0.22$

$0.49 \pm 0.73$

0
Biofilm
$(n=3)$

$0.003 \pm 0.01$

$0.05 \pm 0.01$

$0.03 \pm 0.01$

$0.14 \pm 0.04$

0

$0.02 \pm 0.01$

0

0

0

0

0

$0.24 \pm 0.07$

$0.12 \pm 0.02$
Shepody Bay

$$
\begin{gathered}
\text { C.volutator } \\
(n=5)
\end{gathered}
$$

Polychaetes $(n=8)$

Biofilm $(n=6)$

$0.02 \pm 0.05 \quad 0$

$0.88 \pm 0.44 \quad 0.42 \pm 0.38$

0

$0.04 \pm 0.01$

$1.44 \pm 1.80$

$0.74 \pm 0.43$

$0.02 \pm 0.01$

$7.28 \pm 2.47$

$3.72 \pm 1.24$

$0.10 \pm 0.04$

$0.58 \pm 0.33 \quad 1.09 \pm 0.56$

0

$0.02 \pm 0.01$

$1.18 \pm 0.35 \quad 2.30 \pm 0.77$

$0.05 \pm 0.05 \quad 0$

0

$0.01 \pm 0.02 \quad 0$

0

$0.07 \pm 0.06 \quad 0$

0

$0.01 \pm 0.01 \quad 0$

0

$0.01 \pm 0.02 \quad 0$

0

$11.53 \pm 3.66$

$8.27 \pm 2.20$

$0.18 \pm 0.08$

0

$0.02 \pm 0.05$

0

$3.62 \pm 1.77$

$0.83 \pm 0.32$

$0.07 \pm 0.02$

0

$1.05 \pm 0.65$

0 


\begin{tabular}{|c|c|c|c|c|c|c|}
\hline $\mathrm{C} 18: \ln 9 \mathrm{c}$ & $2.29 \pm 0.28$ & $0.53 \pm 0.48$ & $0.01 \pm 0.01$ & $2.57 \pm 0.63$ & $0.68 \pm 0.33$ & $0.02 \pm 0.01$ \\
\hline $\mathrm{C} 20: \ln 9 \mathrm{c}$ & $0.42 \pm 0.04$ & $0.06 \pm 0.12$ & 0 & $0.51 \pm 0.15$ & $0.37 \pm 0.27$ & 0 \\
\hline $\mathrm{C} 22: \ln 9$ & 0 & 0 & 0 & $0.08 \pm 0.07$ & 0 & 0 \\
\hline $\mathrm{C} 24: \ln 9$ & 0 & 0 & 0 & $0.01 \pm 0.01$ & 0 & 0 \\
\hline$\sum$ MUFAs & $5.18 \pm 1.38$ & $2.36 \pm 1.19$ & $0.13 \pm 0.03$ & $6.77 \pm 2.52$ & $2.95 \pm 1.10$ & $0.09 \pm 0.02$ \\
\hline $\begin{array}{l}\text { Polyunsaturated fatty acids } \\
\text { C18:2n6c }\end{array}$ & $0.61 \pm 0.20$ & $0.23 \pm 0.15$ & $0.01 \pm 0.002$ & $0.83 \pm 0.44$ & $0.16 \pm 0.16$ & $0.02 \pm 0.002$ \\
\hline $\mathrm{C} 18: 3 \mathrm{n} 6$ & $0.04 \pm 0.07$ & 0 & 0 & $0.18 \pm 0.08$ & 0 & 0 \\
\hline $\mathrm{C} 18: 3 \mathrm{n} 3$ & $0.12 \pm 0.06$ & $0.38 \pm 0.26$ & $0.02 \pm 0.01$ & $0.12 \pm 0.06$ & $0.55 \pm 0.35$ & $0.01 \pm 0.01$ \\
\hline $\mathrm{C} 20: 2 \mathrm{n} 6 \mathrm{c}$ & $0.14 \pm 0.03$ & $0.05 \pm 0.10$ & 0 & $0.15 \pm 0.04$ & $0.18 \pm 0.16$ & 0 \\
\hline $\mathrm{C} 20: 3 \mathrm{n} 6$ & 0 & 0 & 0 & $0.06 \pm 0.06$ & $0.01 \pm 0.02$ & $0.01 \pm 0.01$ \\
\hline $\mathrm{C} 20: 3 \mathrm{n} 3$ & 0 & 0 & 0 & $0.07 \pm 0.06$ & $0.05 \pm 0.09$ & 0 \\
\hline $\mathrm{C} 20: 4 \mathrm{n} 6$ & $1.44 \pm 0.27$ & $1.38 \pm 0.12$ & $0.02 \pm 0.004$ & $1.71 \pm 0.34$ & $0.97 \pm 0.29$ & $0.01 \pm 0.01$ \\
\hline C20:5n3 (EPA) & $8.63 \pm 2.40$ & $6.75 \pm 2.64$ & $0.11 \pm 0.02$ & $10.53 \pm 4.66$ & $8.00 \pm 2.65$ & $0.11 \pm 0.03$ \\
\hline $\mathrm{C} 22: 5 \mathrm{n} 3$ & $0.26 \pm 0.06$ & $1.37 \pm 0.65$ & 0 & $0.35 \pm 0.07$ & $1.47 \pm 0.57$ & 0 \\
\hline C22:6n3 (DHA) & $3.84 \pm 0.60$ & $1.26 \pm 0.51$ & $0.02 \pm 0.003$ & $3.92 \pm 0.82$ & $1.49 \pm 0.67$ & $0.02 \pm 0.01$ \\
\hline$\sum_{53}$ PUFAs & $15.09 \pm 3.48$ & $11.42 \pm 3.40$ & $0.19 \pm 0.03$ & $17.91 \pm 6.34$ & $12.87 \pm 4.21$ & $0.18 \pm 0.06$ \\
\hline
\end{tabular}

\section{4}




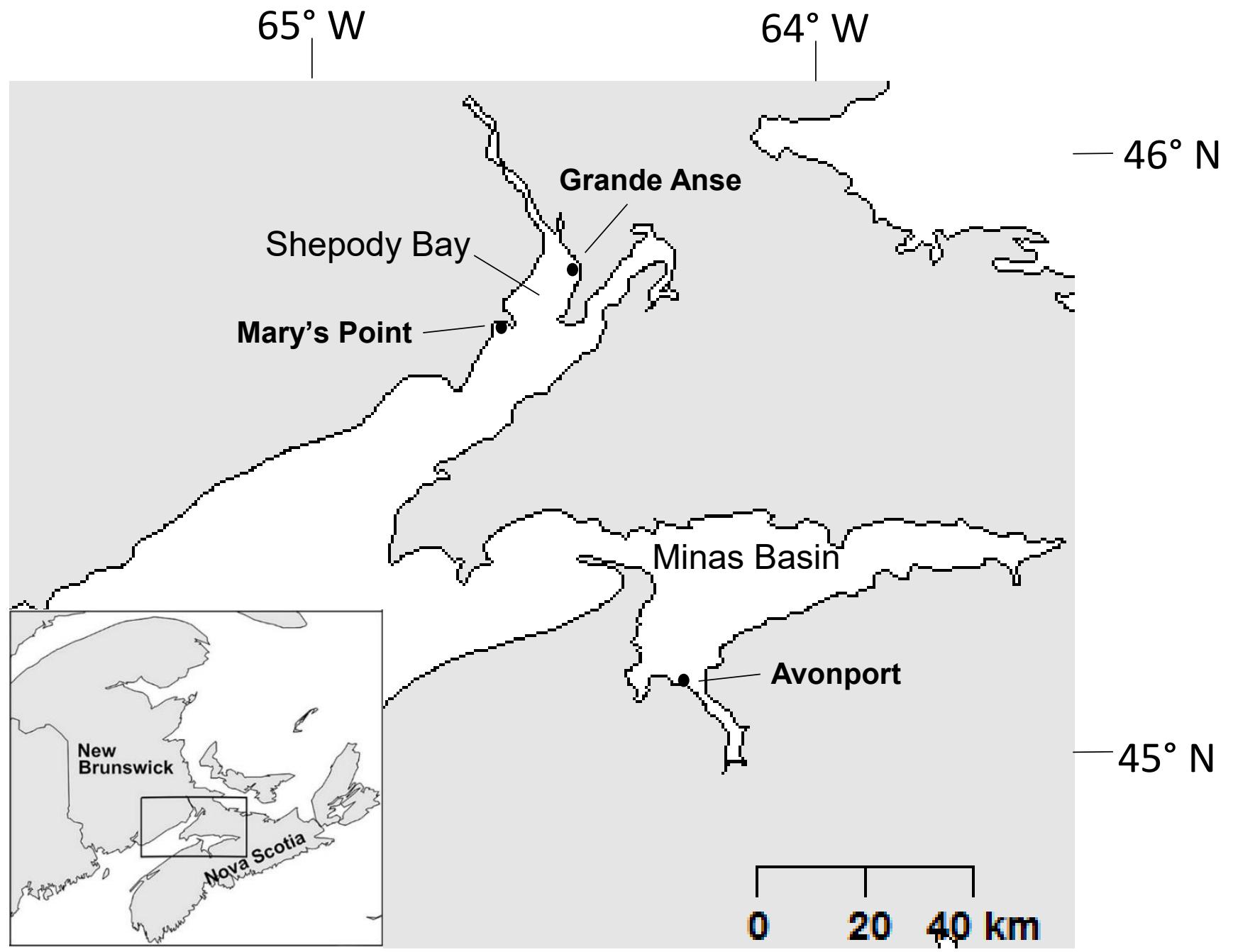



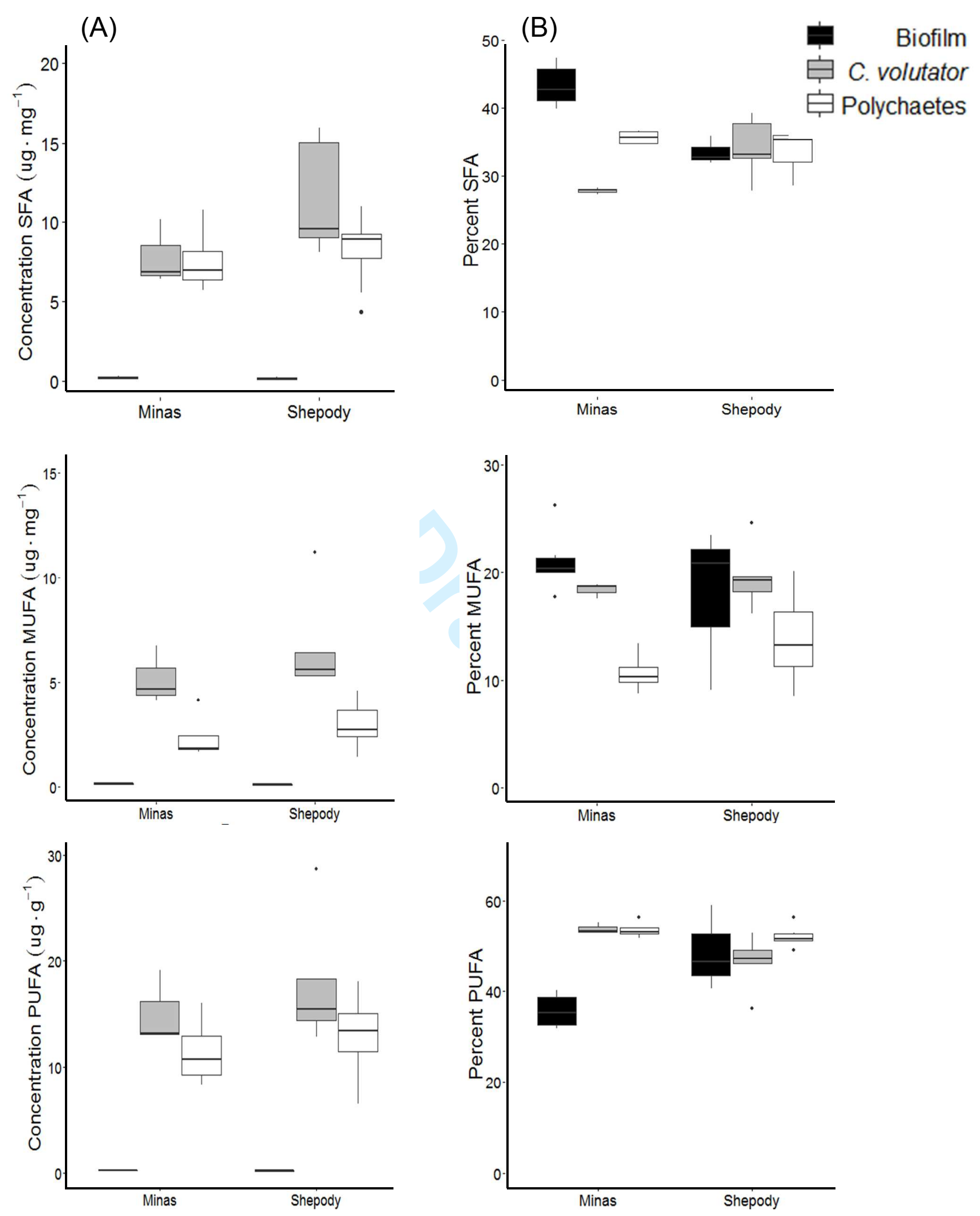

\section{Bay}

https://mc06.manuscriptcentral.com/cjz-pubs 
(A)
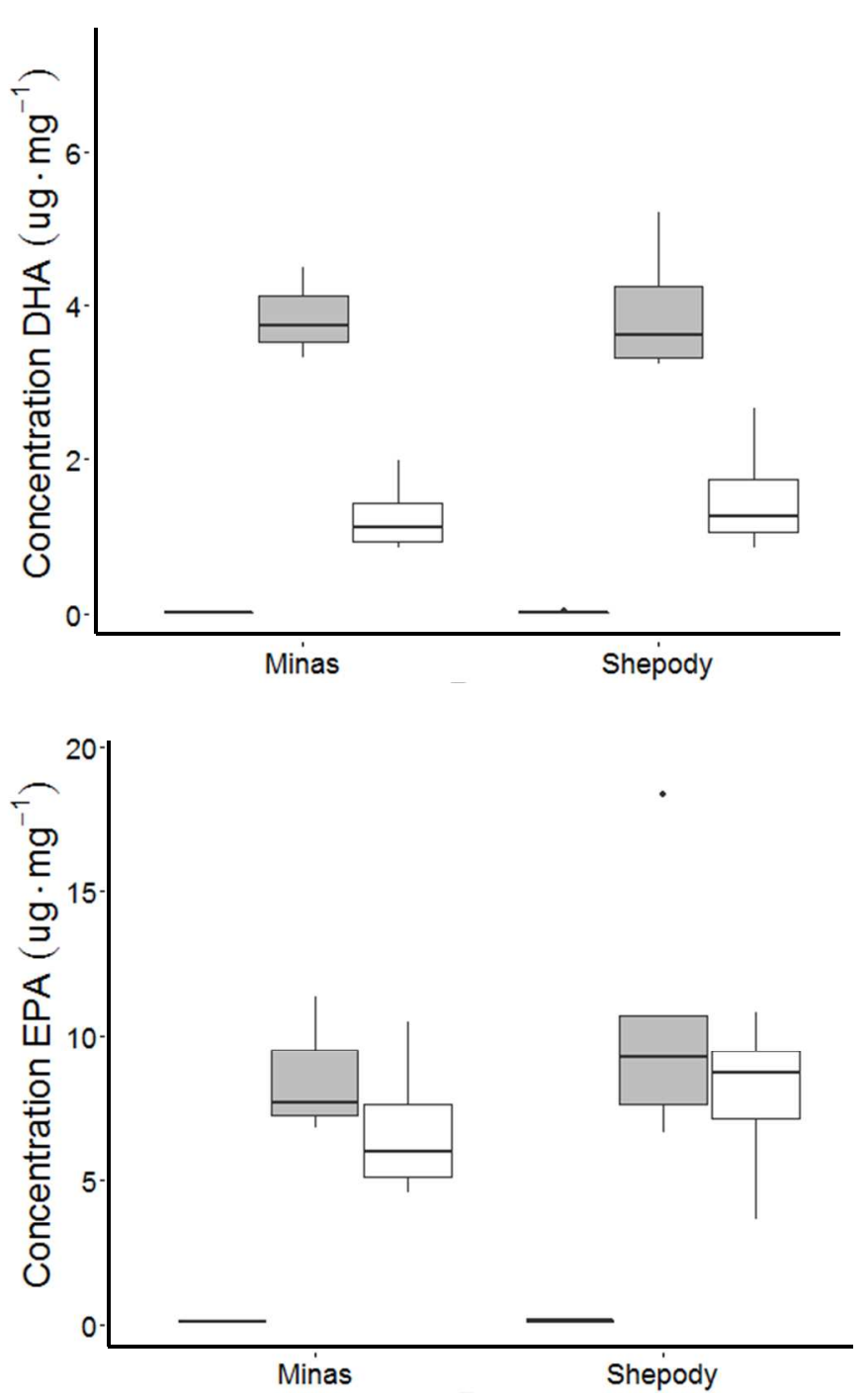

(B)
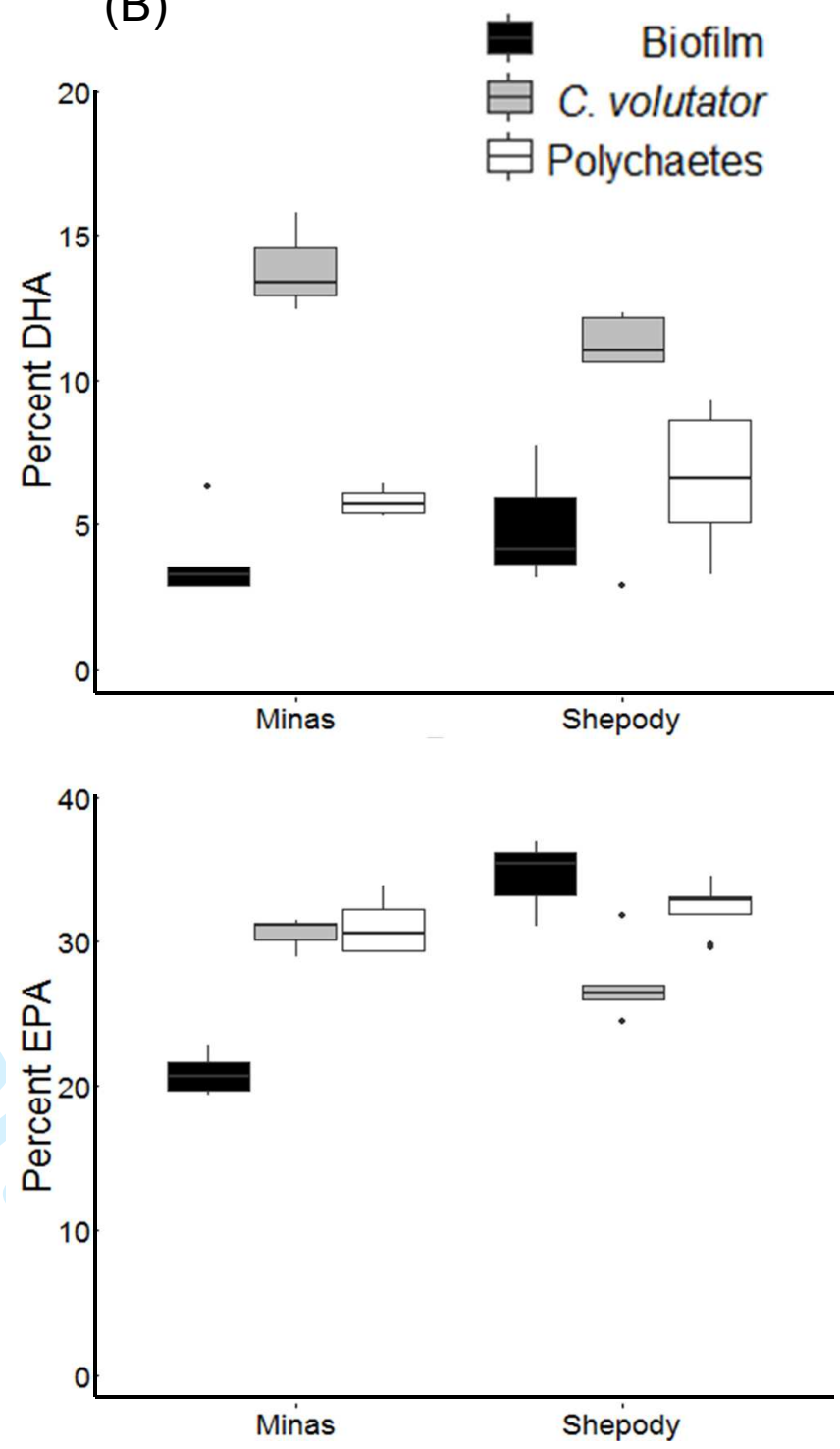

\section{Bay}

